\title{
Liquid-Phase Hydrogenation of Unsaturated Aldehydes: Enhancing Selectivity of Multiwalled Carbon Nanotube- Supported Catalysts by Thermal Activation
}

\author{
Bruno F. Machado, ${ }^{[\mathrm{ac}]}$ Helder T. Gomes, ${ }^{[\mathrm{a}, \mathrm{b}]}$ Philippe Serp, ${ }^{[\mathrm{cc}}$ Philippe Kalck, ${ }^{[\mathrm{c}]}$ and \\ Joaquim L. Faria*[a]
}

\begin{abstract}
Platinum and iridium organometallic precursors are used to prepare nanosized, thermally stable multiwalled carbon nanotube-supported catalysts. The materials are characterized by $\mathrm{N}_{2}$ adsorption at $77 \mathrm{~K}$, temperature-programmed desorption coupled with mass spectrometry, $\mathrm{H}_{2}$ chemisorption, transmission electron microscopy and thermogravimetric analysis; they are tested in the selective hydrogenation of cinnamaldehyde to cinnamyl alcohol under mild conditions ( $363 \mathrm{~K}$ and $1 \mathrm{MPa}$ ). A thermal activation at $973 \mathrm{~K}$ is found to have a very positive
\end{abstract}

effect over both activity and selectivity, leading to selectivities of approximately $70 \%$, at $50 \%$ conversion, regardless of the active metal phase (Pt or Ir). Since no noticeable differences in the metal particle sizes are detected, the results are interpreted in light of an enhanced metal/support interaction. This effect, induced by the removal of oxygenated surface groups, is thought to change the adsorption mechanism of the cinnamaldehyde molecule.

\section{Introduction}

Carbon materials are nowadays one of the most commonly used materials in catalysis and can be used either as a support for different heterogeneous catalysts or as a catalyst themselves. Carbon nanotubes (CNTs) were discovered soon after the successful laboratory synthesis of fullerenes. ${ }^{[1]}$ Since their discovery in 1991 by lijima, ${ }^{[2]}$ CNTs have been the focus of materials research as a result of their unique electronic and mechanical properties, in combination with their chemical stability. ${ }^{[3,4]}$ Promising applications of CNTs include electronic devices, field emitters and mechanical strengthening, hydrogen storage and sensing, energy storage, and catalysts. ${ }^{[5-8]}$

Selective catalytic hydrogenation of organic substrates containing unsaturated functional groups is an important step in the industrial preparation of fine chemicals. As an example, allylic alcohols are obtained from the hydrogenation of the carbonyl group in $\alpha, \beta$-unsaturated aldehydes and are valuable intermediates for the production of perfumes, flavoring additives, pharmaceuticals, and agrochemicals. ${ }^{[9]}$ The development and characterization of catalysts for the selective hydrogenation of $\alpha, \beta$-unsaturated aldehydes has been reviewed by Gallezot and Richard ${ }^{[10]}$ and more recently by Mäki-Arvela et al. ${ }^{[11]}$ The selectivity towards the desired unsaturated alcohols is difficult to achieve because thermodynamics favors the hydrogenation of the $\mathrm{C}=\mathrm{C}$ over the $\mathrm{C}=\mathrm{O}$ bond by about $35 \mathrm{~kJ} \mathrm{~mol}^{-1[12]}$ and because of kinetic reasons as the reactivity of the olefinic bond is higher than that of the carbonyl. Despite these drawbacks, the selectivity towards unsaturated alcohols using heterogeneous catalysts has been improved by changing conditions, such as the nature of the support or the active metal phase.

Activated carbons, xerogels, fullerenes, nanofibers, and nanotubes are important among the carbon family in the hydrogenation of unsaturated aldehydes, such as crotonaldehyde, ${ }^{[13,14]}$ cinnamaldehyde, ${ }^{[15-18]}$ and citral. ${ }^{[19,20]}$ Multiwalled carbon nanotubes (MWCNTs) containing metals such as $\mathrm{Pt}$ or $\mathrm{Pd}$ and promoters such as $\mathrm{Ni}, \mathrm{Ru}$, or Co have been successfully used to selectively hydrogenate either the unwanted $\mathrm{C}=\mathrm{C}^{[21,22]}$ or the desired $\mathrm{C}=\mathrm{O}^{[23,24]}$ bond in cinnamaldehyde. It has been found that selectivity towards the allylic alcohol is highly dependent on the nature of the precious metal used. Metals such as $\mathrm{Pt}, \mathrm{Os}, \mathrm{Ir}, \mathrm{Pd}, \mathrm{Rh}$, and $\mathrm{Ru}$, among others, have been studied, leading to differences in activity and selectivity. Gallezot and Richard ${ }^{[10]}$ reported that unpromoted Ir and Os catalysts are considered to be rather selective for unsaturated alcohol formation whereas $\mathrm{Pt}, \mathrm{Ru}$, and $\mathrm{Co}$ are moderately selective, and $\mathrm{Pd}, \mathrm{Rh}$, and $\mathrm{Ni}$ are nonselective.

A key factor that has been many times overlooked, especially with carbonaceous materials, is the influence of oxygenated surface groups. Depending on the amount of surface groups

\footnotetext{
[a] Dr. B. F. Machado, Dr. H. T. Gomes, Prof. J. L. Faria

Laboratório de Catálise e Materiais (LCM)

Laboratório Associado LSRE/LCM, Departamento de Engenharia Química

Faculdade de Engenharia, Universidade do Porto

Rua Dr. Roberto Frias $s / n, 4200-465$ Porto (Portugal)

Fax: $(+351)$ 225-081-449

E-mail:jlfaria@fe.up.pt

[b] Dr. H. T. Gomes

Departamento de Tecnologia Química e Biológica

Escola Superior de Tecnologia e de Gestão

Instituto Politécnico de Bragança

Campus de Santa Apolónia, 5300-857 Bragança (Portugal)

[c] Prof. P. Serp, Prof. P. Kalck

Laboratoire de Chimie de Coordination UPR CNRS 8241

Composante ENSIACET, Toulouse University,

118 Route de Narbonne, 31077 Toulouse Cedex 4 (France)
} 
and type of support, the outcome of the reaction can be extremely different, changing completely the hydrogenation pathway. ${ }^{[23,25,26]}$

In a previous work ${ }^{[26]}$ we studied the effect of different activation procedures of MWCNT in the platinum dispersion and found that the thermal stability is greatly enhanced when the support is treated with a concentrated nitric acid solution, comparing to air activation and ball billing. The Pt particle size was successfully correlated with the amount of oxygenated surface groups present on the support surface and played an important role in the selective hydrogenation of cinnamaldehyde to cinnamyl alcohol. A high temperature post-reduction treatment at $973 \mathrm{~K}$ enhanced the formation of cinnamyl alcohol up to 17 fold. This increase was attributed to a sintering effect of the active metal phase accompanied by a significant reduction of the amount of surface groups.

In the present work, we report the use of multiwalled carbon nanotube-supported Ir catalysts for the liquid-phase selective hydrogenation of cinnamaldehyde to cinnamyl alcohol. For comparison purposes, the same reaction was carried out under identical conditions with Pt catalysts, as to determine the influence of the metal.

\section{Results and Discussion}

\section{Support characterization}

The production process of MWCNTs gives essentially a nonporous material with all the observed surface area due to adsorption at the external surface of the nanotubes (the inner cavity being mainly inaccessible). The shape of the adsorption isotherms (Figure 1) can be associated to type IV, with a H1 hysteresis loop, characteristic of mesoporous materials. ${ }^{[31]}$

Because MWCNTs are nonporous, the nature of the isotherms can be explained in terms of particle aggregation to form very small inter-particular mesopores. The slight microporous behavior evidenced in the low pressure region $\left(p / p_{0}<0.01\right)$ could be attributed to a reduced number of opened MWCNT tips with very small diameter.

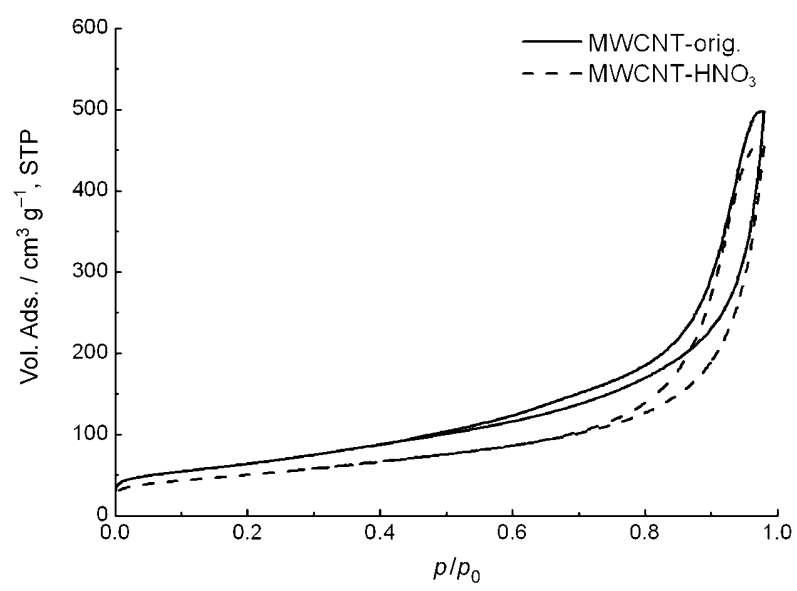

Figure 1. $\mathrm{N}_{2}$ adsorption-desorption isotherms at $77 \mathrm{~K}$ for MWCNT before and after functionalization with nitric acid.
When nitric acid oxidation is carried out, carbon materials often develop large amounts of surface groups, namely carboxylic acid [strong (1) and weak (2); Figure 2], anhydrides (3),
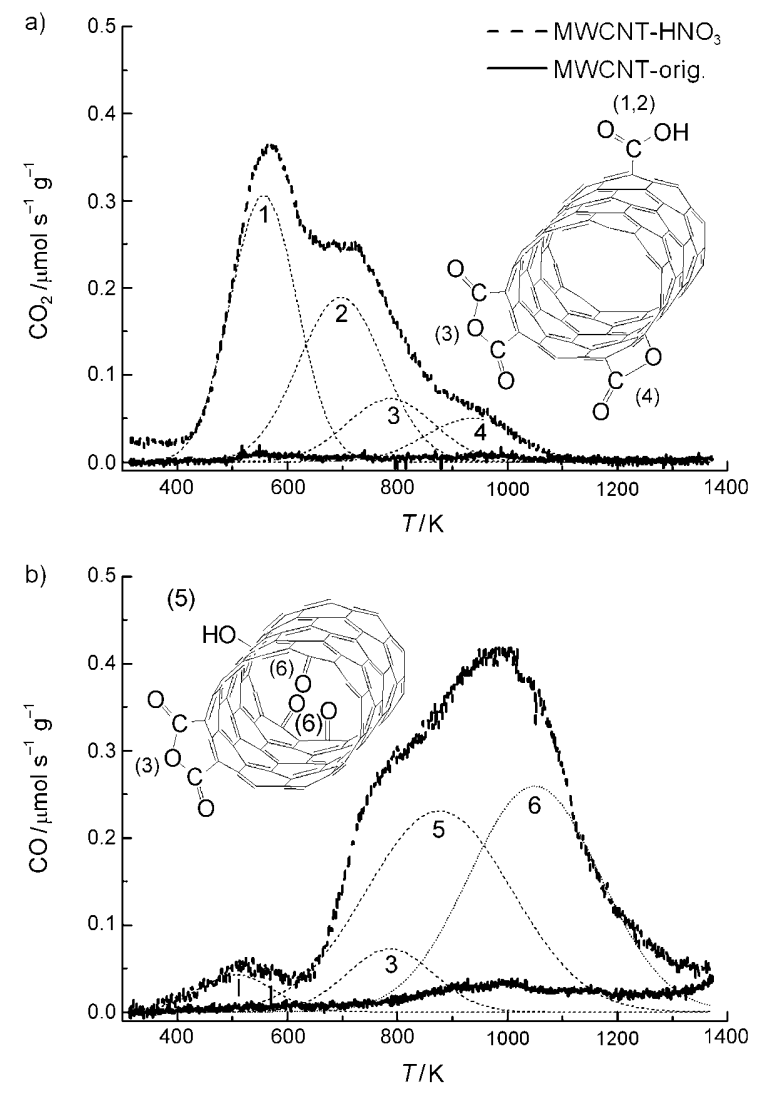

Figure 2. TPD spectra for MWCNT before and after functionalization with nitric acid; deconvolution for functionalized MWCNT: a) $\mathrm{CO}_{2}$ and b) $\mathrm{CO}$ evolution; inset: oxygenated surface groups commonly found after nitric acid oxidation.

lactones (4), phenols (5), ethers, and carbonyl/quinone (6). ${ }^{[32]}$ The distinction between two types of carboxylic acid groups (strongly acidic and weakly acidic) is ascribed to the existence of energetically different sites in surface-oxidized carbons. Temperature-programmed desorption (TPD) experiments performed on the MWCNTs, before and after nitric acid activation (Figure 2) clearly show the difference in the amount of surface groups between both samples.

Untreated MWCNT presents a surface area of $220 \mathrm{~m}^{2} \mathrm{~g}^{-1}$ (Table 1) and a rather inert surface, with a scarce amount of oxygen-containing functionalities released as $\mathrm{CO}$ and $\mathrm{CO}_{2}$ (Table 1). Following nitric acid activation, the surface area of the MWCNTs decreased approximately $20 \%$ to $180 \mathrm{~m}^{2} \mathrm{~g}^{-1}$; at the same time, the amount of oxygen groups released as $\mathrm{CO}$ increased by a factor of 10 whereas those released as $\mathrm{CO}_{2}$ increased over 20 times.

The amounts of the different surface groups were determined by deconvolution of the TPD spectra according to the procedure previously described by Figueiredo et al., ${ }^{[32,33]}$ using multiple Gaussian functions based on the Levenberg-Marquardt algorithm. Following the described procedures, it was 


\begin{tabular}{|c|c|c|}
\hline $\begin{array}{l}\text { Support }\left(S_{B E T} \pm 5\right) \\
\text { Functional groups (release } \\
\text { temperature) }\end{array}$ & $\begin{array}{l}\mathrm{CO}( \pm 20) \\
{\left[\mu \mathrm{mol} \mathrm{g}{ }^{-1}\right]}\end{array}$ & $\begin{array}{l}\mathrm{CO}_{2}( \pm 20) \\
{\left[\mu \mathrm{mol} \mathrm{g}^{-1}\right]}\end{array}$ \\
\hline MWCNT-orig $\left(220 \mathrm{~m}^{2} \mathrm{~g}^{-1}\right)$ & 210 & 60 \\
\hline MWCNT-HNO $3\left(180 \mathrm{~m}^{2} \mathrm{~g}^{-1}\right)$ & 2130 & 1300 \\
\hline $\begin{array}{l}\text { 1. Strong carboxylic acids } \\
(560 \mathrm{~K})\end{array}$ & 120 & 580 \\
\hline 2. Weak carboxylic acids (700 K) & - & 440 \\
\hline 3. Anhydrides (790 K) & 160 & 160 \\
\hline 4. Lactones $(935 \mathrm{~K})$ & - & 110 \\
\hline 5. Phenols ( $885 \mathrm{~K}$ ) & 920 & - \\
\hline 6. Carbonyl/quinones (1050 K) & 920 & - \\
\hline
\end{tabular}

possible to identify high amounts of carboxylic acid groups, phenols, and carbonyl/quinones; and lower amounts of anhydrides and lactones. No deconvolution was carried out for the untreated MWCNT sample due to the very low amounts of $\mathrm{CO}$ and $\mathrm{CO}_{2}$ desorbed. An indication of the MWCNT surface acidity can be provided by the $\mathrm{CO} / \mathrm{CO}_{2}$ ratio, since most acidic groups are released as $\mathrm{CO}_{2}$, whereas the weak acidic and basic groups are released as $\mathrm{CO}$. A strong increase in acidity was observed as $\mathrm{CO} / \mathrm{CO}_{2}$ decreased from 3.4 to 1.6.

\section{Catalyst characterization}

From the textural point of view, metal deposition did not comprise any significant changes to the initial surface area of the support, as some oscillations around $200 \mathrm{~m}^{2} \mathrm{~g}^{-1}$ were observed. Characterization results for the platinum and iridium catalysts can be found in Table 2 . The specific BrunauerEmmett-Teller (BET) surface areas were determined by nitrogen adsorption isotherms at $77 \mathrm{~K}$; the metal loading was determined by inductively coupled plasma (ICP) analysis and the metal particle size was assed by both $\mathrm{H}_{2}$ chemisorption and transmission electron microscopy (TEM) analysis.

Table 2. Specific BET surface areas $\left(S_{B E T}\right)$, metal loading $\left(y_{M}\right)$, and particle size $\left(d_{M}\right)$, determined by $\mathrm{H}_{2}$ chemisorption and TEM analysis for MWCNTsupported Pt and Ir catalysts.

\begin{tabular}{|lllll|} 
Catalyst & $S_{\text {BET }}( \pm 5)\left[\mathrm{m}^{2} \mathrm{~g}^{-1}\right]$ & $y_{M}( \pm 0.1)[w t \%]$ & \multicolumn{2}{c|}{$d_{M}[\mathrm{~nm}]$} \\
& & & $\mathrm{H}_{2}$ chem. & TEM \\
\hline 1\% Pt/MWCNT & 208 & 1.0 & 1.2 & 2.1 \\
$1 \%$ Pt/MWCNT973 & 205 & 0.9 & 2.0 & 1.9 \\
$3 \%$ Pt/MWCNT & 214 & 3.1 & 2.4 & 2.6 \\
$3 \%$ Pt/MWCNT973 & 226 & 3.1 & 4.2 & 6.2 \\
$1 \%$ Ir/MWCNT & 200 & 0.9 & 2.0 & 1.2 \\
$1 \%$ Ir/MWCNT973 & 224 & 0.8 & 2.6 & 1.6 \\
2\% Ir/MWCNT & 166 & 1.7 & 2.0 & 1.1 \\
2\% Ir/MWCNT973 & 176 & 1.7 & 2.7 & 1.5 \\
\hline
\end{tabular}

The oxygenated surface groups, mainly carboxylic acids, acted as anchoring sites and bonded covalently to the metal precursor. The strength of this connection allowed the catalyst to be treated at $973 \mathrm{~K}$, thus removing most surface groups, without any indication of sintering. In addition to their high thermal stability, $1 \mathrm{wt} \%$ catalysts also showed a narrow metal size distribution for platinum and iridium with particles in the range of 2 and $1 \mathrm{~nm}$, respectively (Table 2 ).

In catalysts with higher loadings, metal particles are more likely to be close to each other and, thus tend to form larger clusters, when thermally heated to high temperatures. For the catalyst containing $3 \mathrm{wt} \%$ of Pt, particles aggregated to form clusters of about $6 \mathrm{~nm}$. In the case of Ir catalysts, with a lower metal loading than the $\mathrm{Pt}$ ones, particles remained practically unchanged after the post-reduction treatment (PRT).

Figure 3 shows TEM micrographs of MWCNT-supported $2 \mathrm{wt} \%$ iridium catalysts before and after PRT. From these images, it is evident that no sintering effect occurred as the particles look approximately the same size.

The development of surface groups, in spite of being very useful for the metal deposition as mentioned above, damages the carbon surface structure by introducing high amounts of defects. These defects are usually analyzed with Raman spectroscopy following the intensities of $D$ (diamond-like $\mathrm{sp}^{3}$,

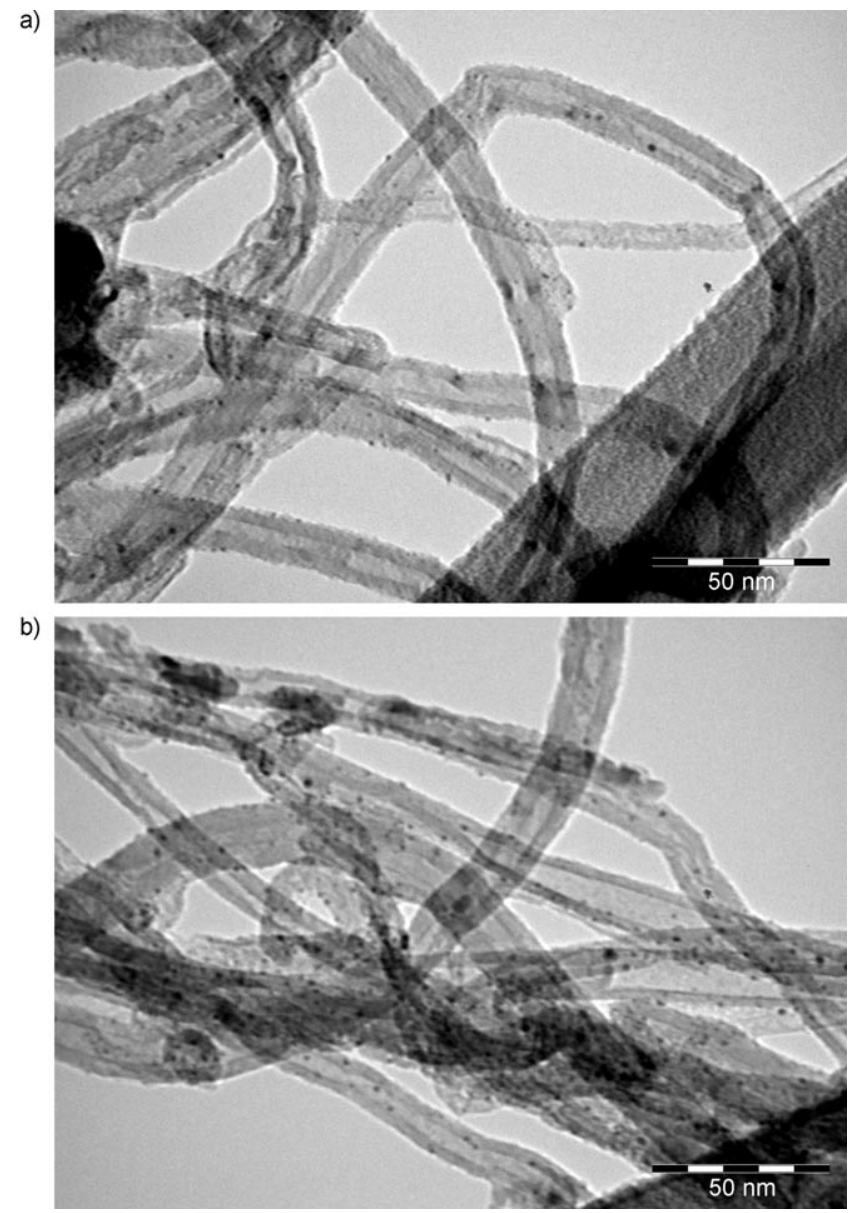

Figure 3. TEM micrographs of $2 \%$ Ir/MWCNT catalysts: a) before and b) after a post-reduction thermal treatment at $973 \mathrm{~K}$. 
$1350 \mathrm{~cm}^{-1}$ ) and $\mathrm{G}$ (graphite-like $\mathrm{sp}^{2}, 1590 \mathrm{~cm}^{-1}$ ) bands. ${ }^{[34]}$ Thermogravimetric analysis (TGA) under an oxidative atmosphere (reconstituted air) can also provide some qualitative results. Using the latter technique, MWCNT- $\mathrm{HNO}_{3}$ revealed only a slight decrease in gasification temperature $(900 \mathrm{~K})$ when compared with the original material $(925 \mathrm{~K})$. This behavior could be explained by an increased local reactivity in the nanotube walls at the defects, leading to a lower oxidation and gasification temperature of the carbon, which is visible in the TGA weight loss profile (Figure 4). In the original material, the gasification process was carried out at higher temperatures due to a low amount of defects, whereas in the nitric acid-treated nanotubes, the high amount of defects introduced in the oxidation step allowed the graphite sheets to be consumed at lower temperatures. This gasification process was also enhanced by the presence of traces of metal catalyst not removed in the purification step.

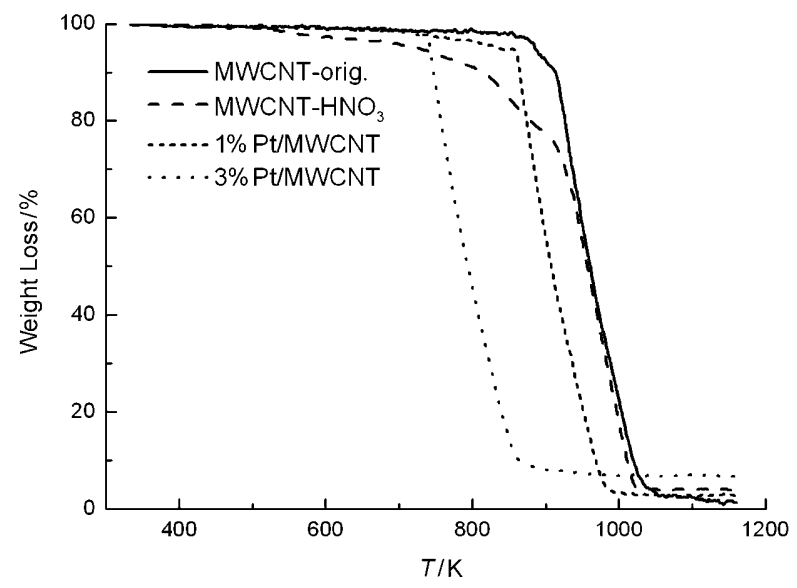

Figure 4. Weight loss as a function of temperature for original MWCNT, functionalized MWCNT, $1 \% \mathrm{Pt} / \mathrm{MWCNT}$ and $3 \% \mathrm{Pt} / \mathrm{MWCNT}$.

The thermal behavior of the MWCNT-supported catalysts was also studied and lower gasification temperatures were detected when compared to the naked supports. The difference regarding the original MWCNTs was due to the enhanced gasification process catalyzed by supported Pt and Ir metal particles. This enhancement was dependent on the amount of metal present at the support surface; as the loading increased, the temperature needed to burn the carbon matrix was lowered (i.e., for Pt: $870 \mathrm{~K}$ for $1 \mathrm{wt} \%$ and $750 \mathrm{~K}$ for $3 \mathrm{wt} \%$ ). These results are in agreement with those published by Stevens and Dahn ${ }^{[35]}$ in which the effect of the Pt loading over the gasification temperature of a carbon black support was studied. Both Pt and Ir catalysts with 1 wt \% metal content exhibited similar behaviors.

\section{Selective hydrogenation of cinnamaldehyde}

Among all the reported operating conditions for selective hydrogenation reactions, the ones used in this work were amongst the mildest reported and thus easier to apply from an industrial point of view. The use of heptane as solvent deals with the high $\mathrm{H}_{2}$ solubility, compared to other commonly used solvents, ${ }^{[36]}$ and with the lower probability of acetal formation during the reaction, ${ }^{[37,38]}$ normally reported when using alcohol-based solvents. The used pressure of $1 \mathrm{MPa}$ was much lower than that reported by others, in which pressures up to $5 \mathrm{MPa}$ were commonly used. The chosen temperature (363 K) was the same as that used in the majority of the published works.

Scheme 1 depicts the proposed reaction scheme for the liquid-phase selective hydrogenation of cinnamaldehyde (CAL). The desired pathway for the preferential hydrogenation of the

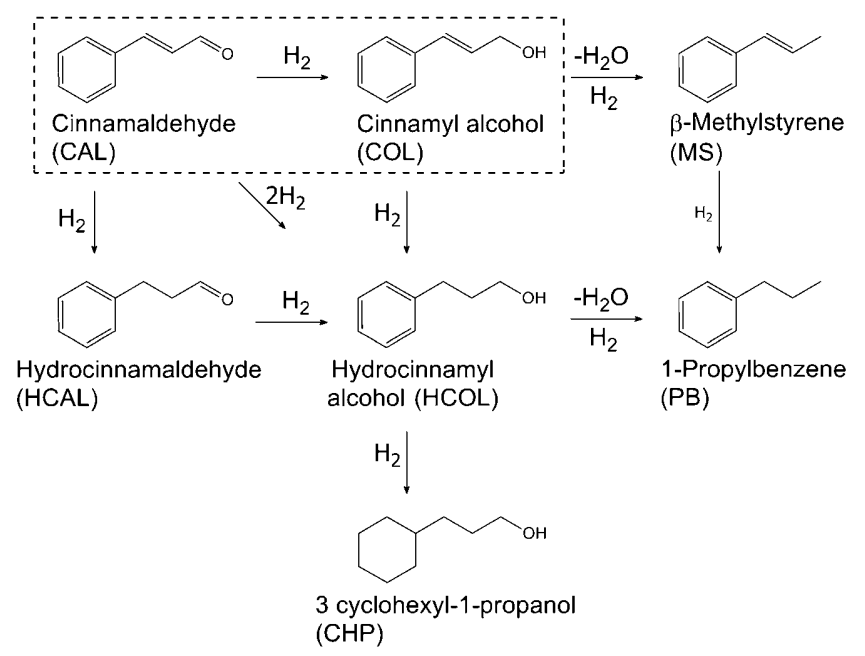

Scheme 1. The selective hydrogenation of cinnamaldehyde using MWCNTsupported Pt and Ir catalysts.

carbonyl group and, thus, the production of cinnamyl alcohol $(\mathrm{COL})$ is highlighted. One parallel route involves the reduction of the olefinic $\mathrm{C}=\mathrm{C}$ bond providing hydrocinnamaldehyde (HCAL); both COL and HCAL can be further hydrogenated to produce the fully saturated hydrocinnamyl alcohol (HCOL). A number of side-products involving the loss of the hydroxy group were detected regardless of the metal nature. The presence of $\beta$-methylstyrene and 1-propylbenzene could indicate a strong adsorption of the hydroxyl groups over the metal sites and a possible poisoning effect. The hydrogenation of the aromatic ring of CAL to give 3-cyclohexyl-1-propanol (CHP) also occurred to a small degree with the catalyst containing the highest metal loading ( $3 \mathrm{wt} \% \mathrm{Pt}$ ). The catalytic results obtained for Pt and Ir catalysts are reported in Table 3.

Pt catalysts without PRT were nonselective towards COL, whereas after the PRT, an increase in activity (i.e., turnover frequency, TOF) and selectivity to COL was observed. Among the catalysts non-subjected to PRT, Ir catalysts showed higher selectivities towards COL. The reason can be explained in terms of a higher processing temperature during the calcination step (necessary to remove the sulfur from the Ir precursor), allowing for a partial removal of the surface groups. Accordingly, the enhancement after PRT was not as pronounced as that for the Pt catalysts. 
Table 3. Turnover frequency and selectivity towards cinnamyl alcohol (COL), hydrocinnamaldehyde (HCAL), hydrocinnamyl alcohol (HCOL), and other products (others) obtained at 50\% conversion with MWCNTsupported Pt and Ir catalysts.

\begin{tabular}{|llllll|} 
Catalyst & TOF $( \pm 0.1)\left[\mathrm{s}^{-1}\right]$ & \multicolumn{4}{c|}{ Selectivity } \\
& & COL & HCAL & HCOL & Others \\
\hline $1 \%$ Pt/MWCNT & 0.9 & 8 & 51 & 13 & 28 \\
$1 \%$ Pt/MWCNT973 & 1.1 & 68 & 10 & 9 & 13 \\
$3 \%$ Pt/MWCNT & 1.5 & 20 & 33 & 21 & 26 \\
$3 \%$ Pt/MWCNT973 ${ }^{[a]}$ & 6.6 & 45 & 18 & 24 & 13 \\
$1 \% \operatorname{lr} /$ MWCNT & 1.5 & 57 & 18 & 13 & 12 \\
$1 \% \operatorname{lr} /$ MWCNT973 & 1.1 & 54 & 19 & 14 & 13 \\
$2 \% \operatorname{lr} /$ MWCNT & 0.8 & 56 & 18 & 10 & 16 \\
$2 \% \operatorname{lr} /$ MWCNT973 & 1.4 & 68 & 17 & 11 & 4 \\
\hline
\end{tabular}

[a] $74 \%$ conversion of cinnamaldehyde.

In Pt-containing catalysts, a clear shift from HCAL to COL selectivity was detected after the PRT. This effect was more pronounced in the case of $1 \% \mathrm{Pt} / \mathrm{MWCNT}$ where an increase from 8 to $68 \%$, at $50 \%$ CAL conversion, was observed (Figure 5) without any indication of particle agglomeration. The selectivity to COL using the $3 \mathrm{wt} \%$ Pt catalyst evidenced a value lower than what would be expected, which was due to the fact that the selectivity was measured at about $75 \%$ conversion. According to a typical COL selectivity profile, there
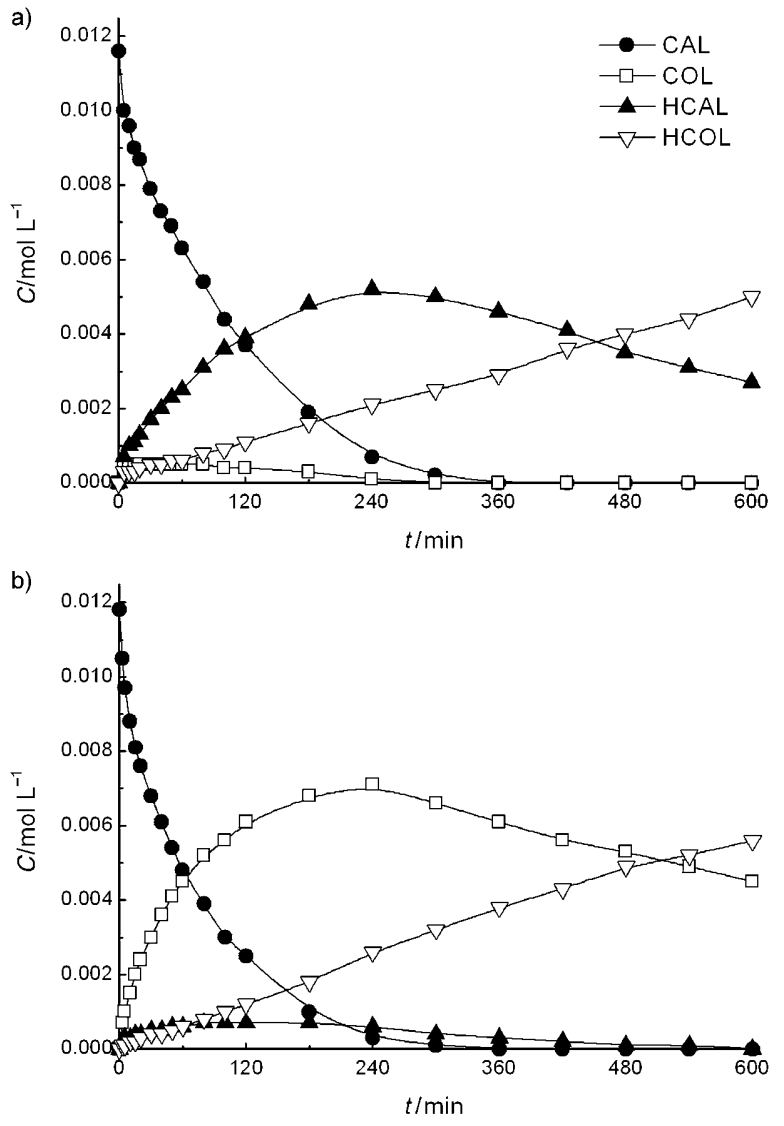

Figure 5. Product distribution for the selective hydrogenation of cinnamaldehyde using $1 \% \mathrm{Pt} / \mathrm{MWCNT}$ catalysts: a) before and b) after a post-reduction thermal treatment at $973 \mathrm{~K}$. is a strong initial increase followed by a rapid decay as it is consumed to yield the saturated alcohol. Hence, a similar selectivity would be expected, at $50 \%$ conversion, to that obtained by $1 \mathrm{wt} \%$ catalyst. Unlike many results in the literature, it was proven here that high selectivities towards the unsaturated alcohol can also be obtained with very small metal particles.

Taking into account the characterization and catalytic results, a comparison can be made between the two different metals. In terms of selectivity to $\mathrm{COL}$, both metals provided excellent results with values of approximately $70 \%$, at $50 \%$ conversion. According to Gallezot and Richard, there is a correlation between the nature of the active metals, their size, and selectivity. ${ }^{[10]}$ According to these authors, Ir catalysts are more selective than Pt ones, considering similar particle sizes; for each metal, selectivities also increased with increasing particle size. In this work, the similar selectivities exhibited by Pt and Ir catalysts can thus be related to their metal particle size. The less selective character of the Pt catalyst is somewhat surpassed by the increased metal particle size, compared to that of the Ir particles.

Because the metal particle size on $1 \mathrm{wt} \%$ catalysts remained relatively unchanged by the high temperature thermal treatment, and the textural properties of the materials remained approximately the same, the shift in selectivity can be attributed to the removal of the oxygenated surface groups. A possible explanation could be related to a metal-support interaction, facilitated by $\pi$-electron transfer from the outer graphite sheets in the MWCNT and the metal. This charge density displacement towards the metal, similar to when promoters are used, confers to the support a nonpolar character, which in turn enhances the $\pi^{*}$ co backbonding and favors the preferential adsorption of the phenyl ring of the CAL molecule on the nonpolar support surface; this enables adsorption and further hydrogenation of the carbonyl group on the metal periphery, which is a similar model to that proposed for $\mathrm{Pt}$ supported on carbon nanofiber (CNF) catalysts by Plomp et al. $^{[39]}$ Other authors also reported that the absence of oxygen surface groups on graphite-supported catalysts led to an electron density enrichment of the metallic particles and to an increased metal-support interaction. ${ }^{[40,41]}$ Hence, with these materials, the selectivity towards hydrogenation of the carbon$\mathrm{yl}$ bond seems to be more affected by the surface chemistry of the support, rather than the metal particle size.

Toebes et al. ${ }^{[25]}$ also studied the influence of oxygen containing surface groups in the hydrogenation of cinnamaldehyde over $\mathrm{Pt} / \mathrm{CNF}$ and detected an increase in activity and $\mathrm{C}=\mathrm{C}$ hydrogenation with selectivities to HCAL as high as $74 \%$ upon their removal. The reason for these results was attributed to the decrease in polarity of the CNF surface. Although our findings support the increase in catalytic activity, a strong selectivity shift towards COL instead of HCAL for both Pt and Ir catalysts was detected in our work. This could be associated to a different adsorption mechanism from CAL due to the different orientation of the graphitic planes in both materials, nanofibers, and nanotubes. Taking into consideration that in both studies the same metal was used, with similar metal particle 
size and similar surface chemistry, the difference on the selectivity shift properties of the materials (between MWCNT and CNF), can be explained by a difference in their structure.

Considering the nature of the support, $\mathrm{Vu}$ et al. ${ }^{[23]}$ carried out a study using Pt and PtRu catalysts supported on different carbon materials. Because both the catalyst preparation and test reaction were kept identical throughout that study, a direct comparison can be made between MWCNT and CNF. The electron transfer from the nanotube support to the metal particles was enhanced after removal of the surface-oxygenated functional groups, and was particularly pronounced for the MWCNT-supported catalysts because of the enhanced mobility of the delocalized $\pi$-electrons in such graphitic planes (mentioned previously). It was also mentioned that for CNFs, this latter effect tends to be less pronounced because of the orientation of the graphene layers and the presence of hydrogen atoms at the external edges of the structure.

Plomp et al. pointed out that the shift in selectivity could be related to the use of different temperatures and pressures. ${ }^{[39]}$ In fact, the conditions used in both studies were distinct, especially regarding the hydrogen pressure: $5 \mathrm{MPa}$ at $383 \mathrm{~K}$ in the work of Toebes et al. ${ }^{[25]}$ and $1 \mathrm{MPa}$ at $363 \mathrm{~K}$ in our work. However, it was shown that there was no trend in selectivity depending on hydrogen pressure; if the support is different, the selectivity may increase, decrease, or remain unchanged. ${ }^{[11]}$ Some studies performed on cinnamaldehyde hydrogenation with Pt supported on carbon materials (i.e., graphite) showed that there was no significant selectivity change with increasing hydrogen pressure on this type of material. ${ }^{[11,42]}$

One additional argument is related to the polarity of the solvent, because we used $n$-heptane whereas Toebes et al. ${ }^{[25]}$ used 2-propanol. There are reports that an increase in polarity increases the selectivity towards $\mathrm{COL}_{1}^{[42,43]}$ which is not the case when comparing our work to that of Toebes.

Based on these results, it is expected that the orientation of the graphitic planes affects the electronic density around the supported metal particles, which in turn hinders the $\mathrm{C}=\mathrm{C}$ bond coordination in cinnamaldehyde due to repulsion, thereby increasing the selectivity toward an unsaturated alcohol by changing the molecule adsorption mode.

\section{Conclusions}

Activation of multiwalled carbon nanotubes with nitric acid created large amounts of oxygen-containing surface groups, namely carboxylic acids, phenols, and carbonyl/quinones, without any significant damage to their surface structure.

Catalysts prepared with Pt and Ir organometallic precursors by wet impregnation presented excellent thermal stability and small metal particles. Higher metal loadings increased the sintering effect after a thermal treatment of the catalysts at $973 \mathrm{~K}$, as opposed to catalysts containing lower metal loadings, in which particles remained practically unchanged.

The stability of the MWCNTs under oxidative atmosphere decreased upon nitric acid activation. This effect was enhanced by the presence of supported metals; the gasification tempera- ture depended on the loading, but not on the nature of the metal.

The liquid-phase hydrogenation of cinnamaldehyde was significantly influenced by the thermal treatment performed to the catalysts at $973 \mathrm{~K}$. Untreated catalysts showed high selectivities towards the production of hydrocinnamaldehyde. After the thermal treatment, supported Pt particles with $2 \mathrm{~nm}$ were quite selective towards the production of cinnamyl alcohol; catalysts containing Ir particles with $1 \mathrm{~nm}$ were also extremely selective to the same product.

The preferential reduction of the carbonyl group seemed to be more affected by the surface chemistry of the support rather than by the metal particle size. This could be attributed to a strong interaction between the metal and the graphite sheets, after the surface group removal.

\section{Experimental Section}

\section{Support synthesis and functionalization}

MWCNTs were produced by chemical vapor deposition (CVD) of ethylene according to a procedure described elsewhere, ${ }^{[27]}$ using $\mathrm{Fe} / \mathrm{Al}_{2} \mathrm{O}_{3}$ as the catalyst. The as-obtained material, consisting of nanotubes, iron, and alumina was then purified by a sulfuric acid treatment to facilitate the total dissolution of alumina and partial elimination of iron contained in the nanotubes (a minimum purity of $97 \%$ was obtained). The MWCNT surface was then modified by maintaining a $7 \mathrm{M}$ nitric acid solution under reflux (MWCNT- $\mathrm{HNO}_{3}$ ) to create carboxylic acid groups $(-\mathrm{COOH}){ }_{,}^{[26,28]}$ which act as anchoring sites for the metal complexes and increase metal dispersion. The nanotubes were then filtered on a hot fritted glass funnel, washed with distilled water until neutrality of the rinsing waters was reached, and dried in an oven for 3 days at $413 \mathrm{~K}$.

\section{Catalyst preparation}

Two different organometallic precursors were prepared according to the metal. Platinum was used as $\left[\mathrm{Pt}\left(\mathrm{CH}_{3}\right)_{2}\left(\mathrm{C}_{8} \mathrm{H}_{12}\right)\right]$ whereas $\left[\operatorname{lr}\left(\mu-\mathrm{SC}\left(\mathrm{CH}_{3}\right)_{3}\right)(\mathrm{CO})_{2}\right]_{2}$ was used as the iridium precursor. The synthesis of the platinum complex involved the preparation of the intermediate $\left[\mathrm{Pt}\left(\mathrm{C}_{8} \mathrm{H}_{12}\right) \mathrm{I}_{2}\right]$, by reaction of $\mathrm{Ptl}_{2}$ (Strem Chemicals, $99 \%$ ) with 1,5-cyclooctadiene (COD, Aldrich, 99\%) in acetone. To prepare the final precursor, further addition of ether, methyllithium solution (Fluka, 5\%) and sodium sulfate was necessary. Additional details can be found elsewhere. ${ }^{[2]]}$ The synthesis of the iridium precursor involved addition of calculated amounts of iridium (III/IV) iodide $\left(\mathrm{Ir}_{3,4}\right.$ Johnson Matthey, 31.8\%), N,N-dimethylformamide (Acros Organics, 99\%), distilled water, and 2-methyl-2-propanethiol (Acros Organics, $99 \%$ ). A more detailed version of the preparation can be found elsewhere. ${ }^{[30]}$ For the preparation of the MWCNT-supported metal catalysts, a calculated mass of metal precursor (to introduce 1 or $3 \mathrm{wt} \% \mathrm{Pt} ; 1$ or $2 \mathrm{wt} \%$ Ir) and MWCNT-HNO $\mathrm{H}_{3}$ was added to $n$ hexane under inert atmosphere. After 1 day under vigorous stirring $(318 \mathrm{~K})$, the catalysts were filtered and dried in an oven at $393 \mathrm{~K}$. The catalysts were calcined in $\mathrm{N}_{2}$, reduced in $\mathrm{H}_{2}$, and flushed with $\mathrm{N}_{2}$ at the reduction temperature $(x \%$ Pt/MWCNT at $623 \mathrm{~K}$ and $x \% \mathrm{Ir} / \mathrm{MWCNT}$ at $773 \mathrm{~K} ; x$ being the metal loading present) in order to remove physisorbed $\mathrm{H}_{2}$. In the case of the Ir catalysts, it was necessary to remove the sulfur contained in the precursor, ${ }_{1}^{[30]}$ and thus a higher temperature than that used for Pt was necessary. A post-reduction treatment (PRT) under $\mathrm{N}_{2}$ at $973 \mathrm{~K}$ was used in indi- 
cated cases to remove the excess oxygenated surface groups ( $x \% \mathrm{Pt} /$ MWCNT973 and $x \% \operatorname{Ir} /$ MWCNT973).

\section{Catalyst characterization}

The textural characterization (BET surface areas, $S_{B E T}$ ) of the materials was based on the $\mathrm{N}_{2}$ adsorption isotherms determined at $77 \mathrm{~K}$ with a Coulter Omnisorp $100 \mathrm{CX}$ apparatus. The metal dispersion was determined by $\mathrm{H}_{2}$ chemisorption at room temperature in an U-shaped tubular quartz reactor after a thermal treatment to remove contaminant species from the catalyst surface. Pulses of $\mathrm{H}_{2}$ were injected through a calibrated loop into the sample at regular time intervals until the area of the peaks became constant. The amounts of $\mathrm{H}_{2}$ chemisorbed were calculated from the areas of the resultant $\mathrm{H}_{2}$ peaks. The $\mathrm{H}_{2}$ was monitored with a SPECTRAMASS Dataquad quadrupole mass spectrometer. Assuming an adsorption stoichiometry, $\mathrm{H} /$ metal (metal=Pt, Ir), of 1 and the formation of spherical particles, it was possible to estimate the mean particle diameter based on the chemisorption results. Hence, based on a surface metal distribution of $1.12 \times 10^{19}$ atoms $\mathrm{m}^{-2}$ for Pt and $1.30 \times$ $10^{19}$ atoms m$^{-2}$ for $I r$, the metal particle size can be calculated from $d_{\mathrm{Pt}}=1.015 / D_{\mathrm{M}}$ and $d_{\mathrm{lr}}=1.099 / D_{\mathrm{M}}$, respectively, where $D_{\mathrm{M}}$ is the metal dispersion $(\mathrm{H} / \mathrm{Pt}$ or $\mathrm{H} / \mathrm{Ir}$ ). TEM was performed in order to confirm the metallic particle size. A Phillips CM12 apparatus operating at $120 \mathrm{kV}$ was used. The samples were dispersed in ethanol, sonicated, and collected on a copper carbon-coated TEM grid. TPD spectra were obtained with a fully automated AMI-200 catalyst characterization instrument (Altamira Instruments), equipped with a quadrupole mass spectrometer (Ametek, Mod. Dymaxion). The catalyst sample $(0.10 \mathrm{~g})$ was placed in a U-shaped quartz tube located inside an electrical furnace and heated at $5 \mathrm{Kmin}^{-1}$ using a constant flow rate of helium equal to $25 \mathrm{~mL} \mathrm{~min}^{-1}$ (STP). For quantification of the $\mathrm{CO}$ and $\mathrm{CO}_{2}$ amounts released during the thermal analysis, calibrations of these gases were carried out at the end of each analysis. Quantification of the metal loading was performed by TGA and ICP. TGA was performed using a Mettler M3 balance. In the TGA experiments, the sample was heated under $\mathrm{N}_{2}$ from 303 to $1173 \mathrm{~K}$ at $25 \mathrm{Kmin}^{-1}$. After $7 \mathrm{~min}$ at $1173 \mathrm{~K}$ in $\mathrm{N}_{2}$, the feed gas was exchanged to air in order to determine the sample ash content. The decrease in sample weight due to gasification was monitored as a function of temperature. Knowing the ash content of the naked support, the metal loading can be easily calculated. The accuracy of this procedure increases for higher metal loadings and requires high amounts of sample for loadings lower than $1 \mathrm{wt} \%$. For tests under an oxidative atmosphere, the sample was heated from $323 \mathrm{~K}$ to $1173 \mathrm{~K}$ at $20 \mathrm{Kmin}^{-1}$.

\section{Catalytic hydrogenation}

Liquid-phase hydrogenation of cinnamaldehyde was studied in a $100 \mathrm{~mL}$ well-stirred stainless steel reactor. The reaction mixture contained heptane $(80 \mathrm{~mL}$, Aldrich, $99 \%)$, cinnamaldehyde $(0.14 \mathrm{~g}$, Fluka, 98\%), decane (Fluka, 98\%, as internal standard for gas chromatography) and catalyst $(0.20 \mathrm{~g})$. Heptane was used as a solvent in order to avoid the formation of acetals, which is common when alcohol-based solvents are used. Prior to each reaction, $\mathrm{N}_{2}$ was bubbled throughout the solution several times to remove traces of dissolved oxygen. The reactor was then pressurized with $\mathrm{H}_{2}$ $(0.3 \mathrm{MPa})$ several times in order to purge the $\mathrm{N}_{2}$. All reactions were performed at $363 \mathrm{~K}$ using a total pressure of $1 \mathrm{MPa}$. Samples were periodically withdrawn to monitor product distribution. The analysis was performed in a DANI GC-1000 gas chromatograph, equipped with a split/splitless injector, a capillary column (WCOT
Fused Silica $30 \mathrm{~m}, 0.32 \mathrm{~mm}$ i.d., coated with CP-Sil 8 CB low bleed/ MS $1 \mu \mathrm{m}$ film), and a flame ionization detector (FID). The results of the reaction runs were analyzed in terms of cinnamaldehyde conversion, turnover frequency, and product selectivity as previously described. ${ }^{[26]}$

\section{Acknowledgements}

This research was carried out under the projects POCI/EQU/ 58252/2004, POCI/FEDER/2010, and SFRH/BD/16565/2004, approved by the Fundação para a Ciência e a Tecnologia (FCT), Programa Operacional (POCTI and POCI) and co-supported by FEDER.

Keywords: aldehydes • hydrogenation • nanotubes supported catalysts $\cdot$ surface chemistry

[1] H. W. Kroto, J. R. Heath, S. C. Obrien, R. F. Curl, R. E. Smalley, Nature $1985,318,162-163$.

[2] S. lijima, Nature 1991, 354, 56-58.

[3] S. B. Sinnott, R. Andrews, Crit. Rev. Solid State Mater. Sci. 2001, 26, 145 249.

[4] P. Serp, M. Corrias, P. Kalck, Appl. Catal. A 2003, 253, 337-358.

[5] C. N. R. Rao, B. C. Satishkumar, A. Govindaraj, M. Nath, ChemPhysChem 2001, 2, 78-105.

[6] J. N. Coleman, U. Khan, W. J. Blau, Y. K. Gun'ko, Carbon 2006, 44, 1624 1652.

[7] B. Coq, J. M. Planeix, V. Brotons, Appl. Catal. A 1998, 173, 175-183.

[8] M. Terrones, Annu. Rev. Mater. Res. 2003, 33, 419-501.

[9] P. L. Mills, R. V. Chaudhari, Catal. Today 1997, 37, 367-404.

[10] P. Gallezot, D. Richard, Catal. Rev.-Sci. Eng. 1998, 40, 81-126.

[11] P. Mäki-Arvela, J. Hájek, T. Salmi, D. Y. Murzin, Appl. Catal. A 2005, 292, $1-49$.

[12] C. Mohr, P. Claus, Sci. Prog. 2001, 84, 311-334

[13] F. Coloma, J. Narciso-Romero, A. Sepulveda-Escribano, F. RodriguezReinoso, Carbon 1998, 36, $1011-1019$

[14] F. Salman, C. Park, R. T. K. Baker, Catal. Today 1999, 53, 385-394.

[15] P. V. Samant, M. F. R. Pereira, J. L. Figueiredo, Catal. Today 2005, 102103, 183-188.

[16] B. F. Machado, H. T. Gomes, P. Serp, P. Kalck, J. L. Figueiredo, J. L. Faria, Catal. Today 2010, 149, 358-364.

[17] J. S. Qiu, H. Z. Zhang, X. N. Wang, H. M. Han, C. H. Liang, C. Li, React Kinet. Catal. Lett. 2006, 88, 269-275.

[18] A. Cabiac, T. Cacciaguerra, P. Trens, R. Durand, G. Delahay, A. Medevielle, D. Plee, B. Coq, Appl. Catal. A 2008, 340, 229-235.

[19] E. Asedegbega-Nieto, A. Guerrero-Ruiz, I. Rodríguez-Ramos, Carbon 2006, 44, 804-806.

[20] F. Qin, W. Shen, C. C. Wang, H. L. Xu, Catal. Commun. 2008, 9, 2095 2098.

[21] Y. Li, G. H. Lai, R. X. Zhou, Appl. Surf. Sci. 2007, 253, 4978-4984.

[22] J. P. Tessonnier, L. Pesant, G. Ehret, M. J. Ledoux, C. Pham-Huu, Appl. Catal. A 2005, 288, 203-210.

[23] H. Vu, F. Gonçalves, R. Philippe, E. Lamouroux, M. Corrias, Y. Kihn, D. Plee, P. Kalck, P. Serp, J. Catal. 2006, 240, 18-22.

[24] H. X. Ma, L. C. Wang, L. Y. Chen, C. Dong, W. C. Yu, T. Huang, Y. T. Qian, Catal. Commun. 2007, 8, 452-456

[25] M. L. Toebes, Y. H. Zhang, J. Hajek, T. A. Nijhuis, J. H. Bitter, A. J. van Dillen, D. Y. Murzin, D. C. Koningsberger, K. P. de Jong, J. Catal. 2004, $226,215-225$.

[26] A. Solhy, B. F. Machado, J. Beausoleil, Y. Kihn, F. Gonçalves, M. F. R. Pereira, J. J. M. Órfão, J. L. Figueiredo, J. L. Faria, P. Serp, Carbon 2008 46, $1194-1207$

[27] M. Corrias, B. Caussat, A. Ayral, J. Durand, Y. Kihn, P. Kalck, P. Serp, Chem. Eng. Sci. 2003, 58, 4475-4482.

[28] R. Giordano, P. Serp, P. Kalck, Y. Kihn, J. Schreiber, C. Marhic, J.-L. Duvail, Eur. J. Inorg. Chem. 2003, 610-617. 
[29] H. C. Clark, L. E. Manzer, J. Organomet. Chem. 1973, 59, 411-428.

[30] P. Serp, R. Feurer, P. Kalck, H. Gomes, J. L. Faria, J. L. Figueiredo, Chem. Vap. Deposition 2001, 7, 59-62.

[31] K. S. W. Sing, D. H. Everett, R. A. W. Haul, L. Moscou, R. A. Pierotti, J. Rouquerol, T. Siemieniewska, Pure Appl. Chem. 1985, 57, 603-619.

[32] J. L. Figueiredo, M. F. R. Pereira, M. M. A. Freitas, J. J. M. Órfão, Carbon 1999, 37, 1379-1389.

[33] J. L. Figueiredo, M. F. R. Pereira, M. M. A. Freitas, J. J. M. Órfão, Ind. Eng. Chem. Res. 2007, 46, 4110-4115.

[34] A. C. Ferrari, J. Robertson, Phys. Rev. B 2000, 61, 14095- 14107.

[35] D. A. Stevens, J. R. Dahn, Carbon 2005, 43, 179-188.

[36] U. K. Singh, M. A. Vannice, Appl. Catal. A 2001, 213, 1-24.

[37] M. Lashdaf, A. O. I. Krause, M. Lindblad, A. Tiitta, T. Venalainen, Appl. Catal. A 2003, 241, 65-75.

[38] L. Q. Zhang, J. M. Winterbottom, A. P. Boyes, S. Raymahasay, J. Chem. Technol. Biotechnol. 1998, 72, 264-272.
[39] A. J. Plomp, H. Vuori, A. O. I. Krause, K. P. de Jong, J. H. Bitter, Appl. Catal. A 2008, 351, 9-15.

[40] A. Guerrero-Ruiz, P. Badenes, I. Rodríguez-Ramos, Appl. Catal. A 1998, $173,313-321$.

[41] M. Cerro-Alarcón, A. Maroto-Valiente, I. Rodríguez-Ramos, A. GuerreroRuiz, Carbon 2005, 43, $2711-2722$.

[42] W. Koo-amornpattana, J. M. Winterbottom, Catal. Today 2001, 66, 277287.

[43] H. Yamada, H. Urano, S. Goto, Chem. Eng. Sci. 1999, 54, 5231-5235.

Received: September 4, 2009

Revised: October 27, 2009

Published online on January 20, 2010 